\title{
Preliminaries of the Decay of Metals versus Petroleum Oils
}

\author{
Suresh Aluvihara*1, Jagath Premachandra \\ ${ }^{1}$ Department of Chemical and Process Engineering, University of Peradeniya, Peradeniya, 20400, Sri Lanka \\ ${ }^{2}$ Department of Chemical and Process Engineering, University of Moratuwa, Katubedda, 10400, Sri Lanka
}

\begin{abstract}
Petroleum oils are predominantly made of various hydrocarbons with trace compounds including corrosive aided compounds that basically known as the salts, organic acids and various forms of sulfur. The scope of the current research was based on the investigations of the effect of salts, organic, elemental sulfur and Mercaptans of crude oils on the corrosion rates of seven different types of ferrous metals that important in the industry of crude oil refining. As the procedure the important corrosive properties of two different selected crude oils and the chemical compositions of the selected ferrous metals were analyzed by the standard instruments and methods. There were determined the corrosion rates of prepared metal coupons from selected ferrous metals with the similar dimensions after certain immersion time periods with respect to both crude oils by the weight loss method while analyzing the corroded metal surfaces through the microscope also simultaneously analyzed the decayed metallic elemental concentrations from metals into crude oils and the variations of initial hardness of the metals. As the foremost outcomes of the existing analysis there were obtained the significantly lower corrosion rates from stainless steels which are having at least $12 \%$ of chromium with sufficient amount if nickel, relatively higher corrosive impact from salts especially at the lower temperatures, formations of ferrous sulfides, ferrous oxides, corrosion cracks and pitting corrosion, significantly decay of copper from Monel metal, higher decay of ferrous from some of carbon steels and slight reductions of the initial hardness of metals after the formations of the corrosion on the metal surfaces.
\end{abstract}

Keywords: Petroleum oils, Corrosiveness, Ferrous metals, Weight loss, Decay, Hardness

\section{Introduction}

Petroleum oils are the dominant earth resources that found from the inner parts of the earth with various composites that mostly included large number of hydrocarbons and tarce components such as the corrosive compounds. In the considerations of such corrosion compounds mainly there were indentified the inpact of various sulfur compounds, organic or naphthenic acids and salts on the decay of metals. According to the definitions of material science the corrosion is usually defined as the formations of the metal sulfide, oxide or hydroxides on the relevant metal surfaces as the results of chemical or electrochemical process with the aid of either strong oxidizing agent or any environment that rich in both water and oxygen (Calister, (2003), Davis and Davis, (2003), Khana, (2009), Singh, (2006)). Furthermore in the chemical engineering theories most of active sulfur compounds are able to play a role of oxidizing a metal such as ferrous because of the relatively higher reactiveness of their functional groups (Ajimotokan, Badmos and Emmanuel, (2009), Alsahhaf, Elkilani and Fahim, (2010), Muller, (1982)).Based on the corrosive aided compounds the process of the corrosion may take a variation with different species of appearances such as the galvanic corrosion, pitting corrosion thermal corrosion and general corrosion. Usually such corrosion processes may have uniqueness of their conditions mainly the concentrations and the temperature (Speight, (1999), Luther and Rickard, (2007)). By considering the scope and the problem statements in the current research there were expected to investigate the impact of salts, organic acids, elemental sulfur and Mercaptans on the corrosion of seven various types of metals which are applicable in thye industry of crude oil refining regarding the various tasks.

\section{Materials and Methods}

According to the scope and the objectives of the current research seven different types of ferrous metals were selected for the experiment of the corrosion rate analysis. Because those metals are widely applicable in the crude oils refining process to fulfil various tasks under different different conditions. The selected metals are given in the below.

Received on February 25, 2019; accepted on 21 July, 2019 Correspondence concerning this article should be addressed to Suresh Aluvihara (e-mailaddress: sureshaluvihare@gmail.com) ORCiDID of S. Aluvihara https://orcid.org/0000-0002-3535-1201 
- Carbon Steel (High) - Transportation tubes, storage tanks

- Carbon Steel (Medium)- Storage tanks, heat exchangers

- Carbon Steel (Mild Steel)- Storage tanks, transportation tubes

- 410-MN:1.8 420-MN:2.8 (Stainless Steel)- Heat exchangers, de-salting unit

- 410-MN:1.7 420-MN:1.7 (Stainless Steel)- Crude distillation columns

- 321-MN:1.4 304-MN:1.9 (Stainless Steel)- Crude distillation columns

- $\quad$ Monel 400- Pre heaters, heat exchangers

The chemical compositions of selected metals were detected by the XRF detector in the percentages of each composed metal and most of non metals as well excluding carbon. By considering the availability and the variety of the compositions two different types of crude oils were selected for the existing research and those are namely as Murban and Das Blend. According to the crude assay the Das Blend is known as a "sour" crude oil because of the relatively high sulfur content of such crude oil which is an important parameter regarding the corrosion (Alsahhaf, Elkilani and Fahim, (2010), Afaf, (2007)). The sulfur contents, organic acid contents, Mercaptans contents and the salt conetnts of both crude oils were measured by the standard test methodologies and instruments as given in the Table 1.

Table 1. Test methodologies of corroisive properties of crude oils

\begin{tabular}{|c|c|c|c|}
\hline Property & Instruments and apparatus & Method & Readings \\
\hline Sulfur content & X-ray fluorsence analyzer & Directly used the crude oil samples to the XRF analyzer. & Direct reading \\
\hline & & Each sample was dissolved in a mixture of toluene and isopropyl & \\
\hline Acidity & Titration apparatus & and titrated with potassium hydroxide. & End point \\
\hline Mercaptans content & Titration apparatus & $\begin{array}{l}\text { Each sample was dissolved in sodium acetate and titrated with silver } \\
\text { nitrate. }\end{array}$ & End point \\
\hline Salt content & Salt analyzer & $\begin{array}{l}\text { Each sample was dissolved in organic solvent and exposed to the } \\
\text { cell of analyzer. }\end{array}$ & Direct reading \\
\hline
\end{tabular}

A batch of similar sized metal coupons were prepared from seven different types of selected metals as six metal coupons from each metal type in equal dimensions bacuse of the necessity of the calculations in the corrosion rates of metal coupons. The prepared metals cupons have been shown in the Figure 1. The prepared metal coupons were divded into fourteen bathches and each batch was consisted three homogeneous metal coupons. The surfaces of such metal coupons were observed by the $400 \mathrm{X}$ lens of an optical microscope to confirm that the metal surfaces are free from corroded particles and also the dimensions and initial weights of such metal coupons were measured. A set of crude oil beakers were arranged as seven Murban crude oils beakers and seven Das Blend crude oils beakers. The devided metal coupons were completely immersed in such crude oils containers as one batch per one crude oil

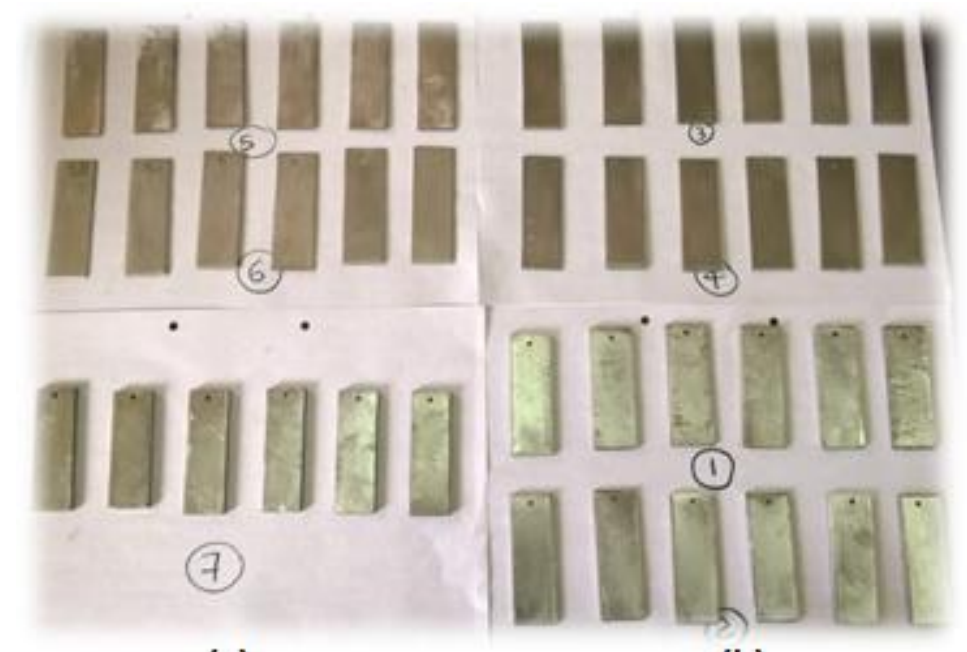

(a) (b) container. The apparatus setup have been shown is the Figure 2. After 15 days from the immersion one metal coupon was taken from crude oil container and the corroded

Fig. 1. Prepared metal coupons surfaces of such metal coupons were observed by 400X lens of an optical microscope for the analysis of the corrosion compou nds qualitatively. The corroded surfaces of such metal coupons were cleaned by the isooctane and sand papers and the final weights of such metal coupons were measured by the analytical balance also with those parameters the corrosion rate of each metal coupon was determined by the relative weight loss method as explained in the below (Afaf, (2007), Okpokwasili and Oparaodu, (2014) ). 


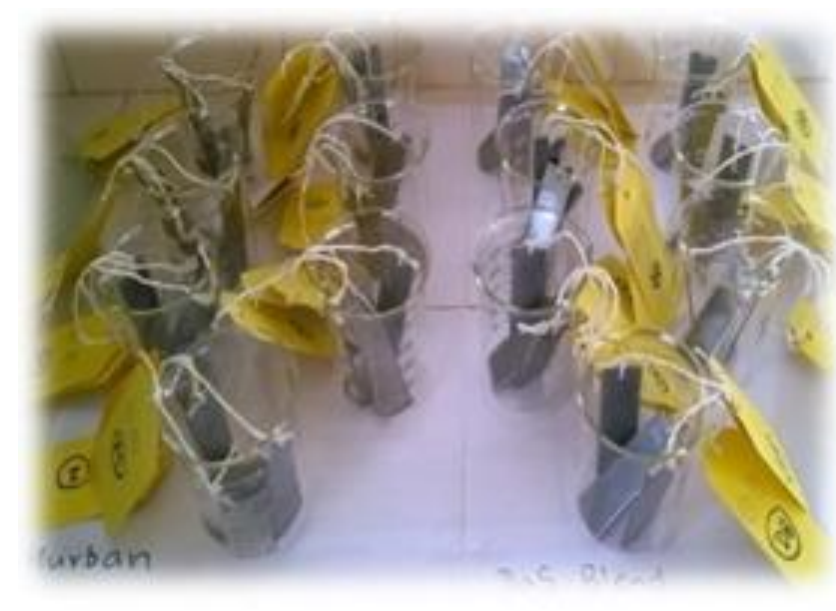

(a)

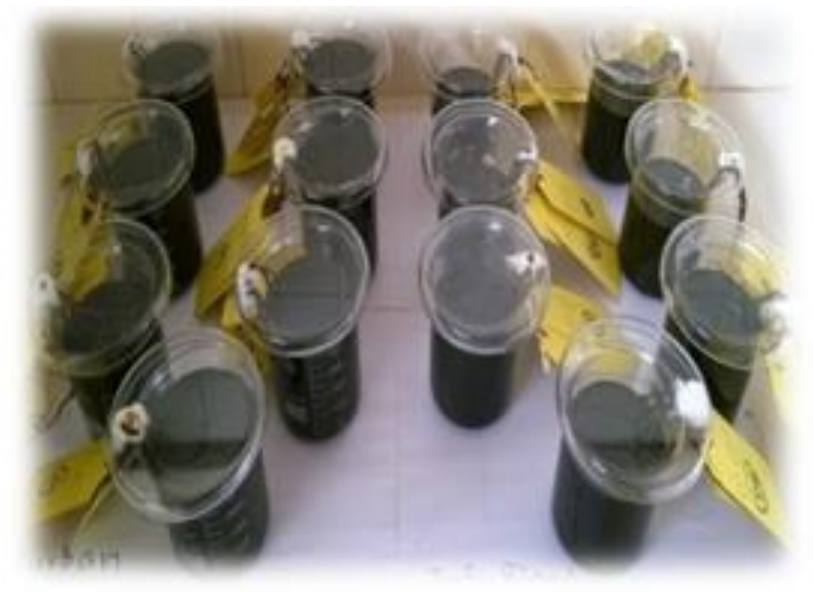

(b)

Fig. 2- (a) Metal coupons and (b) experimental setup

$$
C R=\mathrm{W} * \mathrm{k} /(\mathrm{D} * \mathrm{~A} * \mathrm{t})
$$

Where; $\mathrm{W}$ is weight loss due to the corrosion in grams, $\mathrm{k}$ is a constant $(22,300), \mathrm{D}$ is the metal density in $\mathrm{g} / \mathrm{cm}^{3}, \mathrm{~A}$ is the area of metal piece (inch ${ }^{2}$ ), $\mathrm{t}$ is time (days), and CR is a corrosion rate of metal piece In order of after 30 and 45 days from the immersion the remaining metal coupons were taken out from the crude oil containers as two similar bathes of metal coupons and their corrosion rates were detrmined by the same methodology. Beside of the major experiments the decayed ferrous and copper concentrations from metals into crude oils were determined by the atomic absorption spectroscopy (AAS) because of the observations of conjecture regarding the invisible weight loss of metal coupons during the determinations of the corrosion rates of metal coupons. According to the sample preparation methodology for the instrument $1 \mathrm{ml}$ of each crude oil sample was
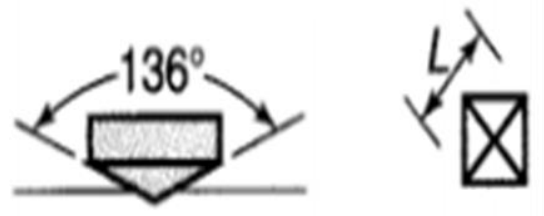

Fig. 3. Indenter of the Vicker's hardness tester diluted in $9 \mathrm{ml}$ of 2-propanol and filtered. Finally the variations of the initial hardness of metal coupons were analyzed by the Vicker's hardness tester based on the confirmations of the process of corrosion and the changes of surface of such metal coupons due to the corrosion. The working principles of the Vicker's hardness tester have been shown in Figure 3 (Calister, (2003), Khana, (2009), Singh (2006)).

$$
\mathrm{HV}=1.854 * \mathrm{P}^{2} / \mathrm{L}^{2}
$$

Where; $\mathrm{P}$ is applied Load on the surface of metal, L is diagonal length of square, and HV is the hardness. As the mandatory measurements the initial hardness and the hardness after the corrosion of each metal coupon were measured by using the Vicker's hardness tester. According to the methodology for one measurement at least the hardness of three positions on each metal coupon were measured and the average value s were interpreted.

\section{Results and Discussion}

The obtained results for the analysis of the chemical compsositions of metals by the X-ray fluorescence have been shortlisted in the Table 2. 
Table 2 Chemical compositions of metals

\begin{tabular}{|c|c|c|c|c|c|c|c|c|c|c|c|c|}
\hline Metal & $\mathrm{Fe}(\%)$ & $\operatorname{Mn}(\%)$ & Co $(\%)$ & $\mathrm{Ni}(\%)$ & $\mathrm{Cr}(\%)$ & $\mathrm{Cu}(\%)$ & $\mathrm{P}(\%)$ & Mo (\%) & $\mathrm{Si}(\%)$ & S (\%) & $\operatorname{Ti}(\%)$ & $\mathrm{V}(\%)$ \\
\hline (1)Carbon Steel & 98.60 & 0.43 & - & 0.17 & 0.14 & 0.37 & 0.12 & 0.086 & 0.09 & - & - & - \\
\hline $\begin{array}{l}\text { (2)Carbon Steel } \\
\text { (Medium) }\end{array}$ & 99.36 & 0.39 & - & - & - & - & 0.109 & - & 0.14 & $<0.02$ & $<0.04$ & - \\
\hline $\begin{array}{l}\text { (3) Carbon Steel } \\
\text { (Mild Steel) }\end{array}$ & 99.46 & 0.54 & $<0.30$ & - & $<0.07$ & - & - & - & - & - & $<0.19$ & $<0.07$ \\
\hline $\begin{array}{l}\text { (4) 410-MN: } 1.8 \\
\text { 420-MN: } 2.8 \\
\text { (Stainless Steel) }\end{array}$ & 88.25 & 0.28 & - & 0.18 & 10.92 & 0.10 & 0.16 & - & 0.11 & - & - & - \\
\hline $\begin{array}{l}\text { (5) 410-MN:1.7 } \\
\text { 420-MN: } 1.7 \\
\text { (Stainless Steel) }\end{array}$ & 87.44 & 0.30 & - & - & 11.99 & - & 0.18 & - & 0.09 & - & - & - \\
\hline $\begin{array}{l}\text { (6) } 321-\mathrm{MN}: 1.4 \\
304-\mathrm{MN}: 1.9 \\
\text { (Stainless Steel) }\end{array}$ & 72.47 & 1.44 & - & 8.65 & 17.14 & - & 0.18 & - & 0.12 & - & - & - \\
\hline (7)Monel 400 & 1.40 & 0.84 & 0.11 & 64.36 & $<0.04$ & 33.29 & - & - & - & - & - & - \\
\hline
\end{tabular}

By considering the obtained results for the chemical compositions of the ferrous metals mainly identified the relatively higher ferrous percentages in carbon steels, moderate ferrous percentages in stainless steels and trace percentage of ferrous in Monel metal. In addition that especially there were identified trace metals in stainless steels such as copper an d nickel. The doping of stainless steels with some d- block metals in trace percentages is an enhancement method of the quality of the raw metal such as the enhancement of the strength of the metal and improvements of the corrosive stability of the metals (Calister, (2003), Davis and Davis, (2003), Khana, (2009)). According to the analysis of the foremost corrosive proeperties of both crude oils the obtained results have been interpreted in the Table 3.

Table 3 Corrosive compounds of crude oils

In the comparison of the corrosive compounds presence in both crude oils Das Blend crude oil was composed relatively higher amounts of organic acids, elemental sulfur, Mercaptans and lower amounts of salts than the Murban crude oil. Although the impact of such corrosive compounds on the metallic corrosion is possible to describe with the required conditions to

\begin{tabular}{lcc}
\hline \multicolumn{1}{c}{ Property } & Murban & Das Blend \\
\hline Sulfur content (Wt. \%) & 0.758 & 1.135 \\
Salt content (ptb) & 4.4 & 3.6 \\
Acidity (mg KOH/g) & 0.01 & 0.02 \\
Mercaptans content (ppm) & 25 & 56 \\
\hline
\end{tabular}
happened such as the temperature. Organic acids are the predominant corrosive compounds presence in crude oils since the occurrence also known as the naphthenic acids that expressed with the formula of RCOOH and the total amount of acids presence in some crude oil is known as the acidity ot total acid number (TAN) of such crude oil. In the process of corrosion the organic acids play a role of strong oxidizing agent and the general chemical reactions are given in the below (Afaf, (2007), Ahmed, Elnour and Ibrahim, (2014), Bota, Nesic, Qu and Wolf, (2010)).

$$
\begin{aligned}
& \mathrm{Fe}+2 \mathrm{RCOOH} \rightarrow \mathrm{Fe}(\mathrm{RCOO}) 2+\mathrm{H}_{2} \\
& \mathrm{FeS}+2 \mathrm{RCOOH} \rightarrow \mathrm{Fe}(\mathrm{COOR}) 2+\mathrm{H}_{2} \mathrm{~S} \\
& \mathrm{Fe}(\mathrm{COOR}) 2+\mathrm{H} 2 \mathrm{~S} \rightarrow \mathrm{FeS}+2 \mathrm{RCOOH}
\end{aligned}
$$

Since the occurrences of crude oils those crude oils may be consisted with different types of halides because of the chemical compositions interior part of the earth. According to the past researches mainly observed three types of salts presence in crude oils namely as $\mathrm{NaCl}$, $\mathrm{CaCl}_{2}, \mathrm{MgCl}_{2}$. At the above temperatures normally such salt molecules covert into $\mathrm{HCl}$ molecules which are showing some inert conditions. When the system is approaching towards the low temperatures such molecules reacted with moisture and water presence in crude oils and ultimaltely formed highly corrosive hydrochloric acids also act as a strong oxiding agent through a process of forming some intermediate products also corrosive compounds such as hydrogen sulfide as given in the chemical reactions below (Ajimotokan, Badmos and Emmanuel, (2009), Alsahhaf, Elkilani and Fahim, (2010), Davis and Davis, (2003), Hassan, (2013), Luther and Rickard, (2007), Okoro and Usman, (2015)).

$$
\mathrm{CaCl}_{2}+\mathrm{H}_{2} \mathrm{O} \rightarrow \mathrm{CaO}+2 \mathrm{HCl}
$$




$$
\begin{aligned}
& \mathrm{HCl}+\mathrm{Fe} \rightarrow \mathrm{FeCl}_{2}+\mathrm{H}_{2} \\
& \mathrm{H}_{2}+\mathrm{S} \rightarrow \mathrm{H}_{2} \mathrm{~S}+\mathrm{H}_{2} \\
& \mathrm{FeCl}_{2}+\mathrm{H}_{2} \mathrm{~S} \rightarrow \mathrm{FeS}+2 \mathrm{HCl}
\end{aligned}
$$

Sulfur is an abundant element in the most of the parts of the earth and in the crude oils also found in various forms of sulfur as a series of different compounds and most of them are highly corrosive compounds because of the reactivity of relevant functional groups. The chemical process and the products may be various forms because of the variety of functional groups. Among the various sulfur compounds that there were idenfied lots of corrosion compounds such as elemental sulfur, Mercaptans, sulfoxides and thiophenes (Alsahhaf, Elkilani and Fahim, (2010), Fang, Nesic and Young, (2008)). The corrosion process due to the elemental sulfur is known as the "localized corrosion" which is happened at about $80^{\circ} \mathrm{C}$ properly and the corrosion process due to the Mercaptans is known as the "sulfidation" also required the supportive temperature in the range of $230-460^{\circ} \mathrm{C}$ for the proper progress. Regarding most of corrosive processes water or the moisture play a dominant background because it tend to be formed both hydrogen sulfide and sulfuric acids which are having higher corrosive potential. The chemical reactions for such processes have been given in the below (Alsahhaf, Elkilani and Fahim, (2010), Davis and Davis, (2003), Luther and Rickard, (2007), Speight, (1999)).

$$
\begin{aligned}
& \mathrm{S}_{8}(\mathrm{~s})+8 \mathrm{H}_{2} \mathrm{O}(\mathrm{l}) \rightarrow 2 \mathrm{H}_{2} \mathrm{SO}_{4}(\mathrm{aq}) \\
& 8 \mathrm{Fe}+\mathrm{S}_{8} \rightarrow \mathrm{FeS}
\end{aligned}
$$

When considering the overall impact of such corrosion compounds it is impossible to determine the corrosive tendancy of crude oils only comparing the magnitude of the corrosive compounds concentration and it must be considered the required conditions

\begin{tabular}{|c|c|c|c|c|}
\hline Metal & $\begin{array}{l}\text { Corrosion Rate after } 15 \\
\text { Days }\left(\mathrm{cm}^{3} \text { inch }^{-1} \text { day }^{-1}\right)\end{array}$ & $\begin{array}{l}\text { Corrosion Rate after } 30 \\
\text { Days }\left(\mathrm{cm}^{3} \text { inch }^{-1} \text { day }^{-1}\right)\end{array}$ & $\begin{array}{l}\text { Corrosion Rate after } 45 \\
\text { Days }\left(\mathrm{cm}^{3} \text { inch }^{-1} \text { day }^{-1}\right)\end{array}$ & $\begin{array}{l}\text { Average Corrosion Rate } \\
\left(\mathrm{cm}^{3} \text { inch }^{-1} \text { day }^{-1}\right)\end{array}$ \\
\hline (1)Carbon Steel (High) & 0.811971 & 0.466425 & 0.068794 & 0.4490632 \\
\hline (2)Carbon Steel (Medium) & 0.817791 & 0.180339 & 0.073358 & 0.3571623 \\
\hline (3) Carbon Steel (Mild Steel) & 0.10973 & 0.048244 & 0.038592 & 0.0655217 \\
\hline $\begin{array}{l}\text { (4) 410-MN: } 1.8 \text { 420-MN: } 2.8 \\
\text { (Stainless Steel) }\end{array}$ & 0.041784 & 0.016075 & 0.011801 & 0.02322 \\
\hline $\begin{array}{l}\text { (5) 410-MN: } 1.7 \text { 420-MN: } 1.7 \\
\text { (Stainless Steel) }\end{array}$ & 0.11626 & 0.011968 & 0.007574 & 0.0452676 \\
\hline $\begin{array}{l}\text { (6) } 321-\mathrm{N}: 1.4 \quad 304-\mathrm{MN}: 1.9 \\
\text { (Stainless Steel) }\end{array}$ & 0.016612 & 0.007453 & 0.005599 & 0.009888 \\
\hline (7)Monel 400 & 0.356263 & 0.034877 & 0.026729 & 0.13929 \\
\hline
\end{tabular}
as well.

According to the determinations of the corrosion rates of metals after certain immersion periods in both crude oils by the weight

\begin{tabular}{|c|c|c|c|c|}
\hline Metal & $\begin{array}{c}\text { Corrosion Rate after } \\
15 \text { Days } \\
\left(\mathrm{cm}^{3} \text { inch }^{-1} \text { day }^{-1}\right)\end{array}$ & $\begin{array}{c}\text { Corrosion Rate after } \\
30 \text { Days } \\
\left(\mathrm{cm}^{3} \text { inch }^{-1} \text { day }^{-1}\right)\end{array}$ & $\begin{array}{c}\text { Corrosion Rate after } \\
45 \text { Days } \\
\left(\mathrm{cm}^{3} \text { inch }^{-1} \text { day }^{-1}\right)\end{array}$ & $\begin{array}{l}\text { Average Corrosion Rate } \\
\left(\mathrm{cm}^{3} \text { inch }^{-1} \text { day }^{-1}\right)\end{array}$ \\
\hline (1)Carbon Steel (High) & 0.350249 & 0.224901 & 0.024738 & 0.1999627 \\
\hline (2)Carbon Steel (Medium) & 0.481055 & 0.140654 & 0.05911 & 0.2269396 \\
\hline (3) Carbon Steel (Mild Steel) & 0.162883 & 0.141093 & 0.100635 & 0.1348702 \\
\hline $\begin{array}{l}\text { (4) 410-MN: } 1.8420-\mathrm{MN}: 2.8 \\
\text { (Stainless Steel) }\end{array}$ & 0.044146 & 0.034035 & 0.006149 & 0.0281102 \\
\hline $\begin{array}{l}\text { (5) 410-MN: } 1.7420-\mathrm{MN}: 1.7 \\
\text { (Stainless Steel) }\end{array}$ & 0.053701 & 0.034841 & 0.016363 & 0.0349681 \\
\hline $\begin{array}{l}\text { (6) 321-MN:1.4 304-MN:1.9 } \\
\text { (Stainless Steel) }\end{array}$ & 0.022894 & 0.006503 & 0.002825 & 0.0107404 \\
\hline (7)Monel 400 & 0.061554 & 0.037655 & 0.016067 & 0.0384254 \\
\hline
\end{tabular}
loss method the obtained results have been given in the Table 4 and Table 5.

Table 4 Corrosion rates of metals in Murban crude oil

Table 5 Corrosion rates of metals in Das Blend crude oil 
The graphical representations of above results have been interpreted in the Figure 4. and Figure.5.

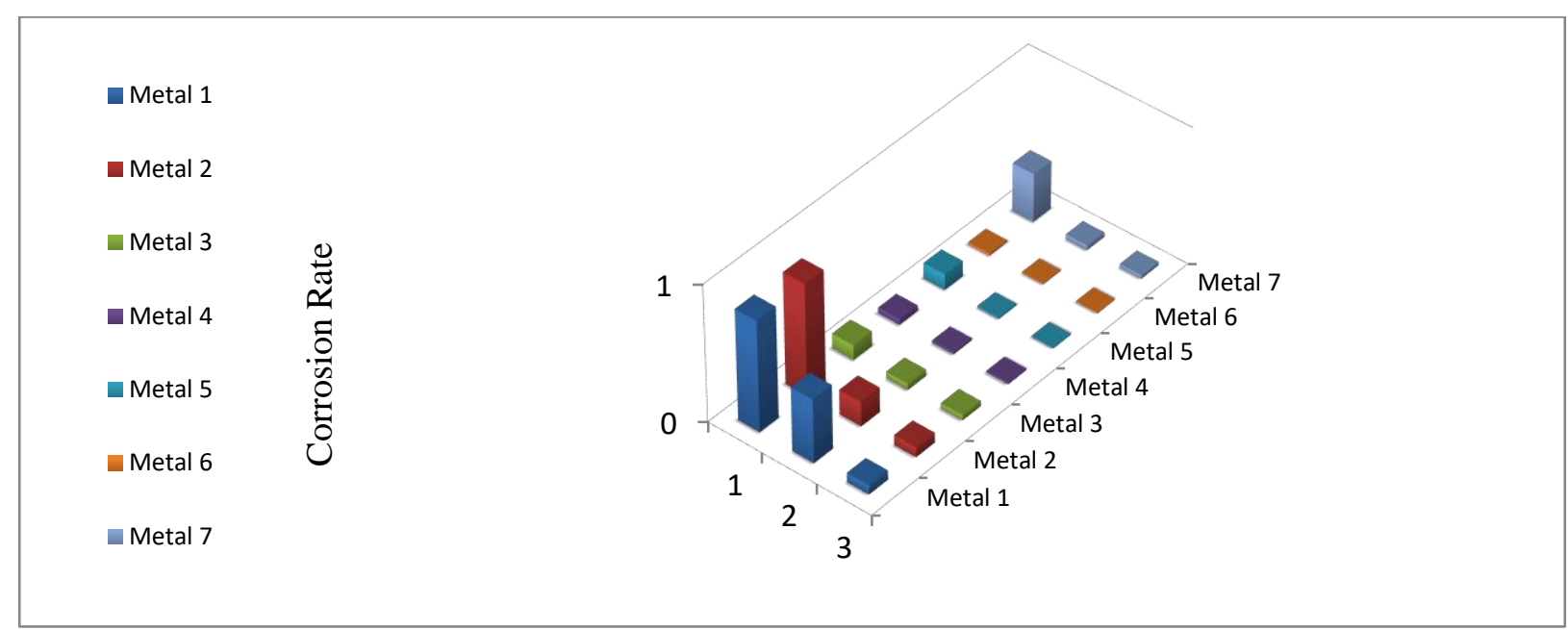

Fig. 4 Corrosion rates of metals in Murban crude oil after 15, 30 and 45 days immersion periods

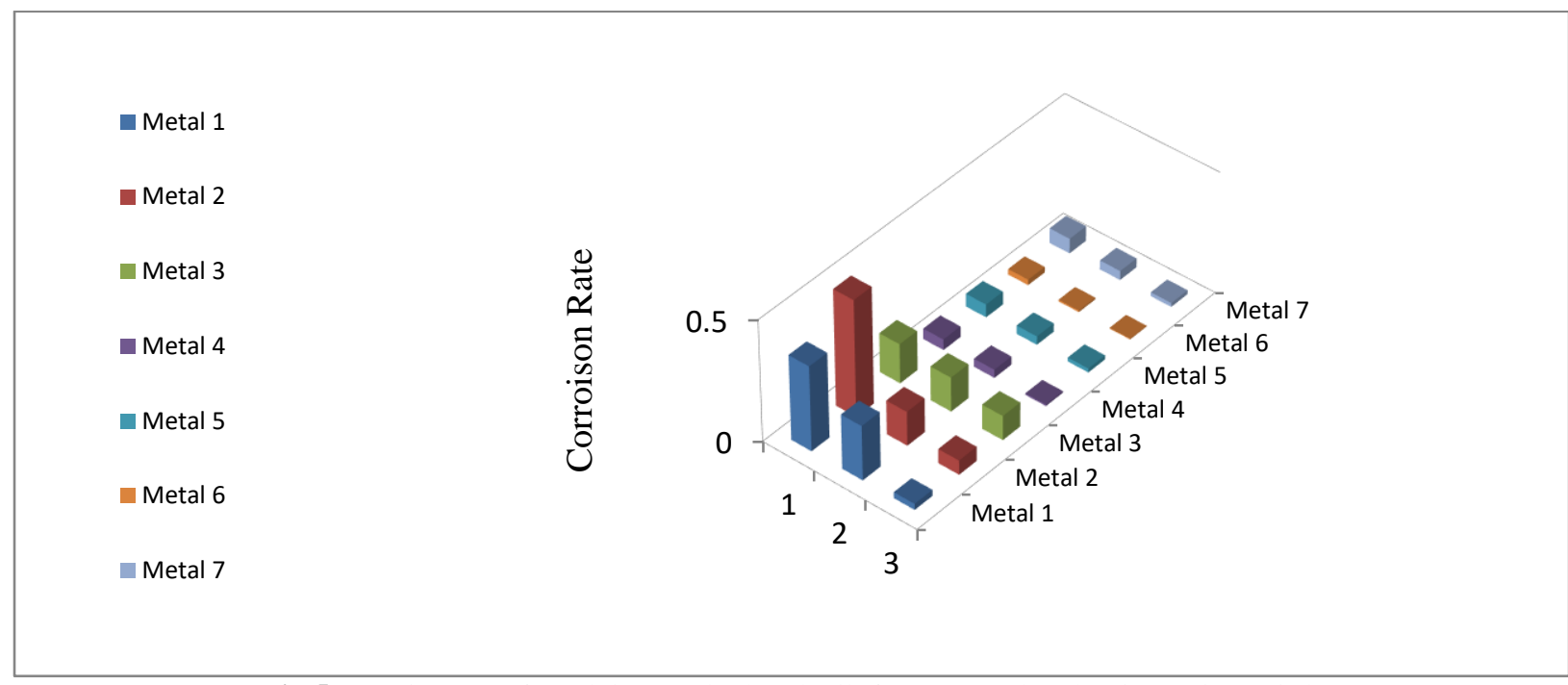

Fig. 5 Corrosion rates of metals in Das Blend crude oil after 15, 30 and 45 days immersion periods

By considering the summary of above results the conclsion of the corrosion rates of metals the average corrosion rates of metal coupons have been shown in the Figure6. According to the above distribution there were observed the higher coroison rates from carbon steels, moderate corrosion rates from Monel and lower corrosion rates from stainless steels. Especially in the corrosion rates among the stainless steels the lowest corrosion rates were observed from 321-MN:1.4 304-MN:1.9 (Stainless Steel) with respect to both crude oils. When paying the attentions on the chemical composition of 321-MN:1.4 304-MN:1.9 (Stainless Steel) it was composed $18 \%$ of chromium and $\sim 8.65 \%$ nickel. In the stainless steels at least $12 \%$ of chromium and sufficient amount of nickel tend to create a self corrosive protection film on the metal surface which is able to prevent the corrosion in a few of times. Therefore, with the obtained results that it is possible to conclude the corrosive protection ability of metal are high when having the chemical composition at least 12\% of chromium with sufficient amount of nickel (Khana, (2009), Bolton, (1994), Calister, (2003)). In the comparison of the corrosion rates of metals in both crude oils four types of metals showed their

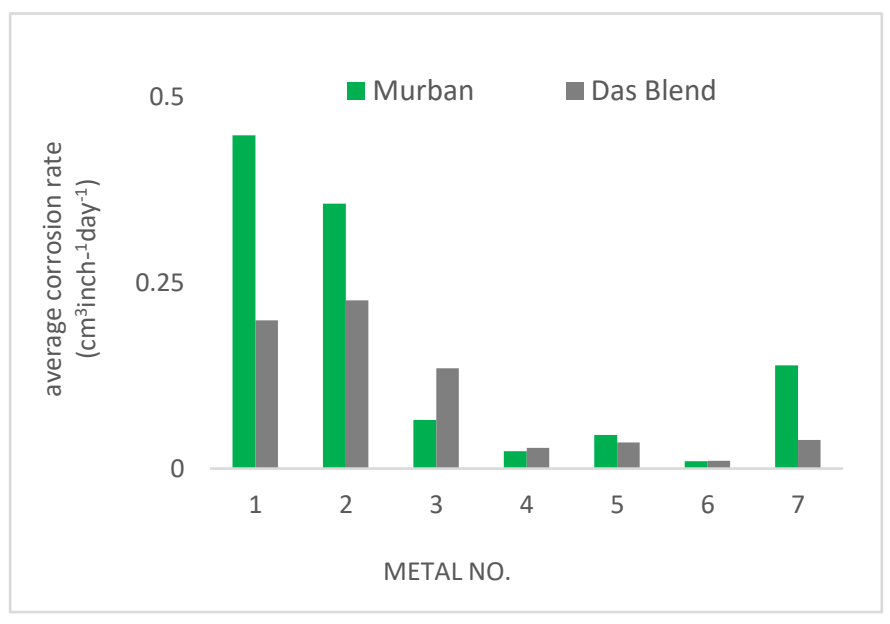

Fig. 6 Average corrosion rates of metals 
higher corrosion rates in Murban crude oil while other three types of metals were showing their higher corrosion rates in Das Blend crude oil. When creating a linkage between these results and corrosive properties of both crude oils it is possible to build some opinion that the impact of the salts on the metallic corrosion is grater than the overall impact of other corrosive compounds at the room temperature (Hashemi and Smith, (2006), Luther and Rickard, (2007)). Although it is much adequate to suggest some improvements of the experiments to have better results and discussion. The improvements have been noticed in the followings:

- Perform the corrosion rate test for several various temperature series.

- Analyze more corrosive compounds other than the analyzed compounds and their impact also with required compounds such as the temperature.

- Also determination of the corrosion rates of metals by some adavanced digital corrosion analysis instruments in addition to the weight loss method for more accurate results.

The variations of the corrosion rates of metals with the exposure time in both crude oils have been interpreted in the Figure 7. By considering the two of above distributions that there can be seen some similar distributions regarding most of metal types. Normally there were found the reductions of the corrosion rates with the exposure time and this observation may be used as the confirmations of the applicability of the weight loss method for the various materials because it indicates the inversely proportional relationship between the corrosion rate and immersion time in the liquid (Afaf, (2007), Okpokwasili and Oparaodu, (2014) ).. The each above distribution is following such rule well. In addition the incident that reduction of the corrosion rate with the exposure time is possible to explain with the simple theory that the initially formed corrosion layer may act as some kind of barrier for the further corrosion (Khana, (2009), Bolton, (1994), Calister, (2003)).
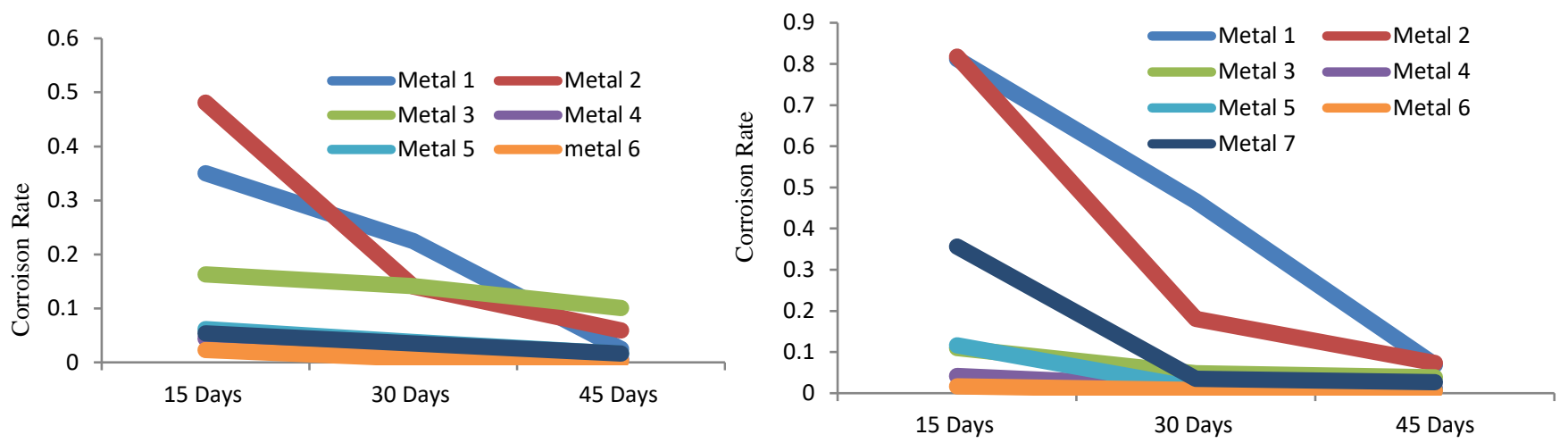

Fig. 7 Variations of the corrosion rates of metals with the exposure time in (left) Murban and (right) Das Blend crude oils

According to the microscopic analysis of the corroded metal surfaces basically there were observed some specific corrosion compounds mainly with the aid of their visible appearances as highlighted in the Figure 8. In the identification of the corrosion compounds on the metal surfaces mainly identified a few of specific corrosion compounds through The results of the analysis of the decayed metal concentrations in to crude oils by the atomic absorption spectroscopy (AAS) have been interpreted in the Table 7. According to the above results the summarized outcome for the decayed ferrous and copper concen trations from metals into crude oils have been shown in the Figure 9 and Figure 10. By referring the above results mainly it van be concluded the significant decay of copper from Monel metal and higher decay of ferrous from carbon steels into crude oils also found highest corrosion rates from such metals. As the special observation $s$ there were observed zero decays of ferrous from stainless steels into crude oils also found the lower corrosion rates from such metals. According to the theoretical explanations of the decay of metals into crdue oils the suitable mechanism is the theory of the repulsive of electrons and protons. After the formations of the corrosion compounds on the metals surfaces such compounds may not be remained om the metal surfaces longer because of the repulsive and attractive forces between successive electrons and protons of such compounds (Khana, (2009), Bolton, (1994), Calister, (2003), Khana, (2009)). Then it is possible to conclude the decay of metals into crude oils is happened unser the mechanism of corrosion of the metals in crude oils and the decay of metal may cause the incident of irregular corrosion cracks and pitting cororison that discussed in the microscopic analysis section. According to the analysis of the variations of the initial hardness of metals by the Vicker's hardness tester the obtained results have been interpreted in the Figure $\mathbf{1 1}$ and Figure 12. 
Table 7 Decayed metal concentrations into crude oils

\begin{tabular}{lccc}
\hline Metal & Crude Oil & Fe Concentration/ppm & Cu Concentration /ppm \\
\hline Carbon Steel (High) & Murban & 0.47 & - \\
& Das Blend & 1.10 & - \\
Carbon Steel (Medium) & Murban & 0.54 & - \\
& Das Blend & 0.02 & - \\
Carbon Steel (Mild Steel) & Murban & -0.08 & - \\
& Das Blend & -0.48 & - \\
410-MN: 1.8 420- MN: 2.8 (Stainless Steel) & Murban & -0.65 & - \\
& Das Blend & -0.78 & - \\
410-MN: 1.7 420-MN: 1.7 (Stainless Steel) & Murban & -0.71 & - \\
321-MN:1.4 304-MN:1.9 (Stainless Steel) & Das Blend & -0.79 & - \\
Monel 400 & Murban & -0.44 & - \\
& Das Blend & -0.17 & - \\
\end{tabular}
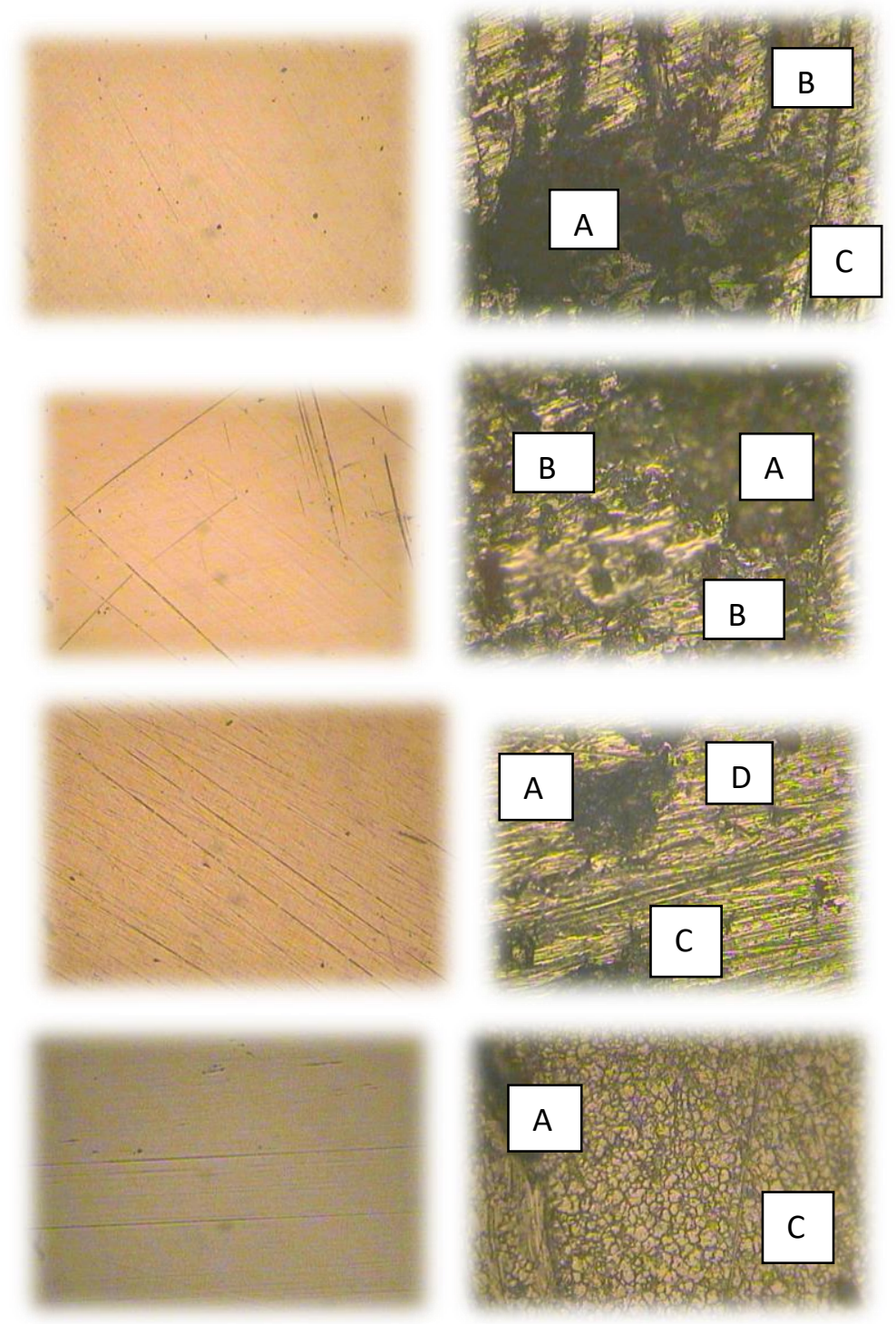

Fig.8 Specific features of corrosion 


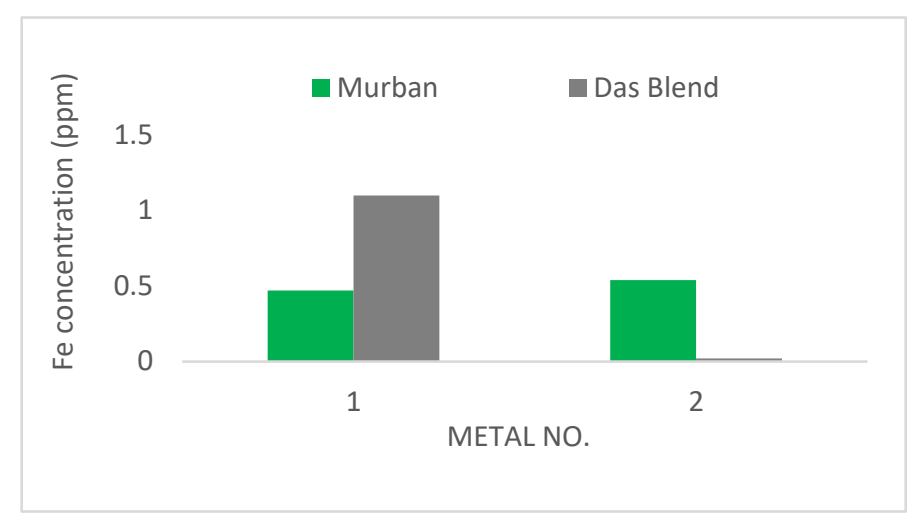

Fig. 9 Decayed ferrous concentrations into crude oils

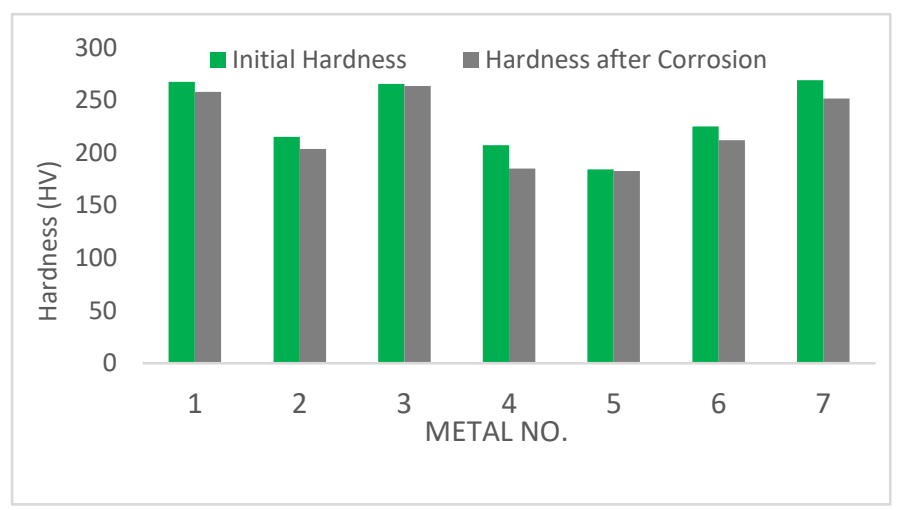

Fig. 11 Deductions of the initial hardness of metal coupons in Murban

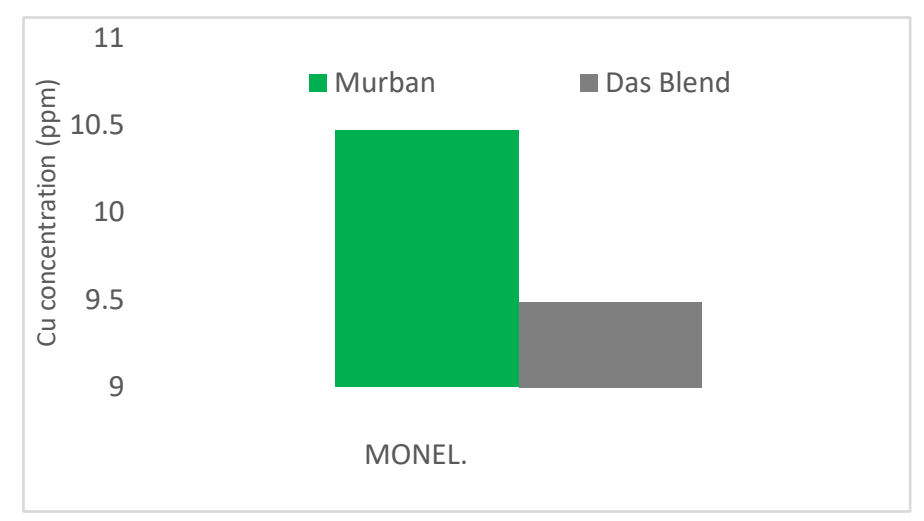

Fig. 10 Decayed copper concentrations into crude oils

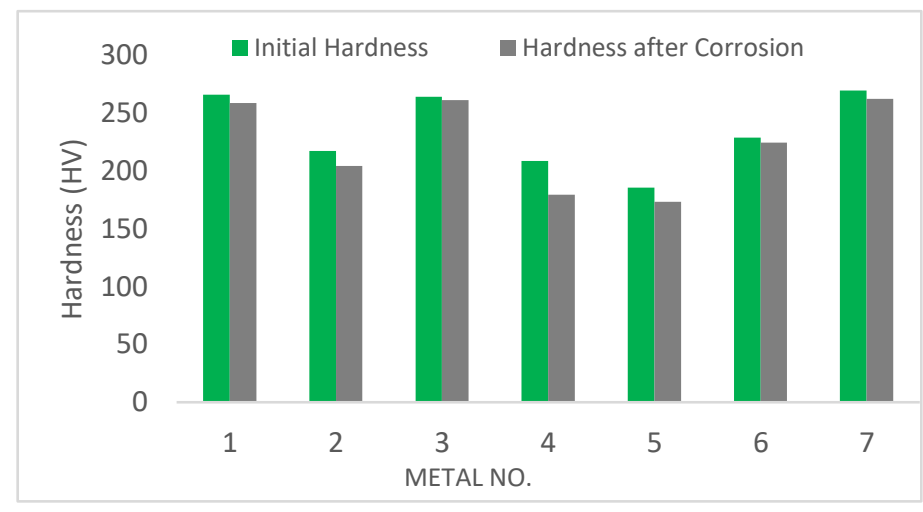

Fig. 12 Deductions of the initial hardness of metal coupons in Das Blend

By considering the above graphs that it is easy to identify slight reductions of the intial hardess of most of metals after the formations of the corrosion on the metal surfaces and this incident also possible to explain with the theory of electron repulsive because after the formations of the corrosion compounds on the metallic surfaces such surfaces are facing for some unstable conditions due to the repulsive and attractive forces between the successive electrons and protons. Also the corroded metal surfaces are contaminated with heterogeneous composites and the hardess of the outer layer may be differ from the initial hardness of the metals (Khana, (2009), Bolton, (1994), Calister, (2003), Singh, (2006)). Therefore, the reductions of the initial hardness can be used as the confirmation of the formations of the corrosion on the metal surfaces and also unable to emphasize some linkage between the parameters of corrosion rates and the deductions of the initial hardness of metals due to the corrosion.

\section{Conclusion}

Under the study of this research that thare were observed some inmoartant primiminaries which are also following the theortical concepts of chemical engineering and material engineering such as the relatively lower corrosion rates from stainless steels which are also having chemical compositions of $\sim 12 \%$ of chromium with sufficient amounts of nickel, significant impact from salts on the metallic corrosion when comparing with the impact of other corrosive compounds, formations of the $\mathrm{FeS}, \mathrm{Fe}_{2} \mathrm{O}_{3}$, corrosion cracks and pits on the metal surfaces, significant decays of ferrous and copper from carbon steels and Monel also zeroth decay of any metallic element from stainless steels and slight reductions of the initial hardness of most of metals consequently with the formations of the corrosion.

\section{Acknowledgements}

The author glad to remember the great support from the laboratory staff members, technical officers and minor staff on the relevant research works.

\section{Nomenclature}

A area of metal piece

CR corrosion rate of metal piece In order of after 30 and 45 days from the immersion

D the metal density $\left[\right.$ inch $\left.^{2}\right]$,

$\left[\mathrm{cm}^{3}\right.$ inch- ${ }^{1}$ day $\left.^{-1}\right]$

$\left[\mathrm{g} / \mathrm{cm}^{3}\right]$ 


$\begin{array}{ll}\text { HV } & \text { the hardness number } \\ \text { K } & \text { constant } \\ \text { L } & \text { diagonal length of square, } \\ \text { P } & \text { applied Load on the surface of metal } \\ \text { T } & \text { time } \\ \text { W } & \text { weight loss due to the corrosion }\end{array}$

$\left[\mathrm{kgf} / \mathrm{mm}^{2}\right]$

$[-]$

[kgf

[days]

\section{References}

Afaf G. A., "Corrosion Treatment of High TAN Crude," PhD. Thesis, University of Khartoum, Khartoum, Sudan, (2007).

Ahmed I.M., M.M. Elnour and M.T. Ibrahim, "Study the Effects of Naphthenic Acid in Crude Oil Equipment Corrosion," Journal of Applied and Industrial Sciences, 2, 255-260, (2014).

Ajimotokan H. A., A. Y. Badmos, and E. O. Emmanuel, “Corrosion in Petroleum Pipelines,” New York Science Journal, vol.2, no.5, pp. 36-40, (2009).

Alsahhaf T.A., A. Elkilani, and M.A. Fahim, Fundamentals of Petroleum Refining, Amsterdam: Radarweg Press, (2010).

Bolton W., Engineering Materials Technology, London, B. H Newnes Limited, (1994).

Bota G. M., S. Nesic, D. Qu, and H.A. Wolf, "Naphthenic Acid Corrosion of Mild Steel in the Presence of Sulfide Scales Formed in Crude Oil Fractions at High Temperature," presented at International Corrosion Conference and Expo, (2010).

Calister W. D., An Introduction of Materials Science and Engineering, NewYork: John Wiley and Sons, Inc, (2003).

Davis M.E., and R.J. Davis, Fundamentals of Chemical Reaction Engineering, New York: McGraw-Hill, (2003).

H. Fang, S. Nesic and D. Young, "Corrosion of Mild Steel in the Presence of Elemental Sulfur," presented at International Corrosion Conference and Expo, (2008).

Hashemi J., W.F. Smith, Foundations of Material Science and Engineering, $4^{\text {th }}$ Ed. New York: McGraw-Hill, (2006).

Hassan N. S., "The Effect of Different Operating Parameters on the Corrosion Rate of Carbon Steel in Petroleum Fractions," Eng. and Tech. Jour., 31, 1182-1193, (2013).

Khana O.P., Materials Science and Metallurgy, New Delhi, Dhanpet Rai and Sons, (2009).

Luther G.W., and D. Rickard, "Chemistry of Iron Sulfides," Chem. Rev., 107,514-562, (2007).

Muller M., "Theoretical Considerations on Corrosion Fatigue Crack Initiation," Metallur. Trans., 13, 649-655, (1982).

Okoro L.N., and A.D. Usman, "Mild Steel Corrosion in Different Oil Types," Int. Jour.of Sci. Res. and Innov. Tech., 12, 9-13, (2015).

Okpokwasili G. C., K. O. Oparaodu, "Comparison of Percentage Weight Loss and Corrosion Rate Trends in Different Metal Coupons from two Soil Environments," Int. Jour. of Envi. Biorem. \& Biodeg., 2, 243-249, (2014).

Singh R., Introduction to Basic Manufacturing Process and Engineering Workshop, New Delhi, New Age International Publication, (2006).

Speight J.G., Eds., The Chemistry and Technology of Petroleum, New York: Marcel Dekker, (1999). 